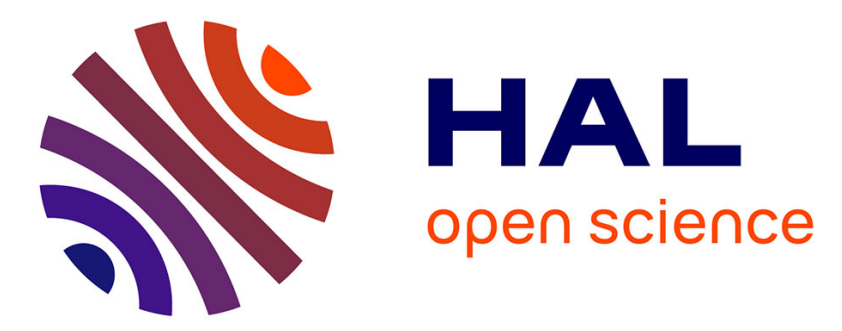

\title{
Crystallization of carbon tetrachloride in confined geometries
}

Adil Meziane, Jean-Pierre E. Grolier, Jean-Marie Nedelec, Mohamed Baba

\section{To cite this version:}

Adil Meziane, Jean-Pierre E. Grolier, Jean-Marie Nedelec, Mohamed Baba. Crystallization of carbon tetrachloride in confined geometries. Faraday Discussions, 2007, 136, pp.370-381. 10.1039/b616128f . hal-00174455

\section{HAL Id: hal-00174455 \\ https://hal.science/hal-00174455}

Submitted on 24 Sep 2007

HAL is a multi-disciplinary open access archive for the deposit and dissemination of scientific research documents, whether they are published or not. The documents may come from teaching and research institutions in France or abroad, or from public or private research centers.
L'archive ouverte pluridisciplinaire HAL, est destinée au dépôt et à la diffusion de documents scientifiques de niveau recherche, publiés ou non, émanant des établissements d'enseignement et de recherche français ou étrangers, des laboratoires publics ou privés. 


\title{
Crystallization of carbon tetrachloride in
}

\section{confined geometries}

\author{
Adil Meziane ${ }^{1}$, Jean-Pierre E. Grolier², Mohamed Baba² and \\ Jean-Marie Nedelec $^{3^{*}}$ \\ ${ }^{1}$ Laboratoire de Photochimie Moléculaire et Macromoléculaire, UMR CNRS \\ 6005 \\ ${ }^{2}$ Laboratoire de Thermodynamique des Solutions et des Polymères, \\ UMR CNRS 6003 \\ ${ }^{3}$ Laboratoire des Matériaux Inorganiques, UMR CNRS 6002
}

\section{TransChiMiC}

Ecole Nationale Supérieure de Chimie de Clermont Ferrand \& Université Blaise Pascal, 24 Avenue des landais 63177 Aubière Cedex, FRANCE.

\footnotetext{
* Corresponding author :

E-mail j-marie.nedelec@univ-bpclermont.fr

Phone $0033(0) 473407195$

Fax $\quad 0033(0) 473407108$
} 


\begin{abstract}
The thermal behaviour of carbon tetrachloride confined in silica gels of different porosity was studied by differential Scanning Calorimetry. Both the melting and the phase transition at low temperature were measured and found to be inextricably dependant upon the degree of confinement. The amount of solvent was varied through two sets of experiments, sequential addition and original progressive evaporation allowing the measurement of the DSC signals for the various transitions as a function of the amount of $\mathrm{CCl}_{4}$. These experiments allowed the determination of transition enthalpies in the confined state which in turn allowed the determination of the exact quantities of solvent undergoing the transitions. A clear correlation was found between the amounts of solvent undergoing the two transitions (both free and confined) demonstrating that the formation of the adsorbed layer $t$ does not interfere with the second transition. The thickness of this layer and the porous volumes of the two silica samples were measured and found to be in very close agreement with the values determined by gas sorption.
\end{abstract}

Keywords: thermoporosimetry, confinement, crystallisation, nanoporous materials 


\section{Introduction}

The peculiar behaviour of liquids in confined geometry has attracted a lot of interest in particular during the past ten years. A comprehensive review has been published in 2001 [1]. The case of water [2,3] is particularly relevant because of the numerous works dealing with water and also because of obvious practical applications. The revival in the interest in transitions in confined geometry undoubtedly comes from the considerable progress in the preparation of nanoporous materials with controlled pore size and with spatially controlled pore distribution and connectivity. In this context discovery of MCM type materials [4] has played an important role. The use of organized molecular systems (surfactants) to limit spatially the condensation of alkoxide precursors is now common and has been extended to various systems and various pore organizations. The availability of such porous materials with controlled porosity, and to some extent with tuneable porosity, has lead to an increased interest for the study of crystallisation in confined geometry. Practical interest of liquids in porous materials is also very widespread and the case of oil recovery is a major example. The chemistry of water in clouds is also greatly affected by confinement effects.

More importantly, the research devoted to the preparation of nanocrystals with a good control of both crystal size and size distribution has been incredibly expanding in the last twenty years [5]. In particular semi-conducting nanocrystals or quantum dots have been the subject of many research papers [6,7] due to the possible observation in these materials of a direct quantum effect correlated to the size of the crystals.

Porous materials appeared to be ideal candidates for the preparation of such nanocrystals, utilizing the pores as nanoreactors where the crystallization of the desired material could be confined. In particular abundant examples concerning MCM-41 and SBA-15 mesoporous silicas templates can be found in the literature, see [8,9] for instance. Another very interesting example of crystallization in confined geometries is Biomineralization [10,11]. 
Biomineralization is a complex process in which the solution conditions, organic template, and crystal confinement coordinate to yield nanostructured composite materials with controlled morphology and mechanical and structural properties. Over the past few decades, research has examined various aspects of this mineralization process both by characterizing those found in nature and by creating synthetic composites.

Another field in which crystallization in confined geometries play a major role is polymer science. Numerous examples demonstrate how the confinement can modify the kinetics of crystallization of polymers and also the morphology of the crystals [12].

All these selected examples demonstrate how crucial it is to get information concerning crystallization in confined geometries. In particular the energetic of crystallization in confining media is not well documented.

The well known modification of the freezing point temperature of liquids in confined geometry has led to the development of characterization techniques for the measurement of porosity in solids. Such techniques are based upon the Gibbs-Thomson equation $[13,14]$ which relates the shift $\Delta \mathrm{T}$ of the crystallization temperature to the pore size of the confining material according to [15]:

$$
\Delta T=T_{p}-T_{0}=\frac{2 \sigma_{S L} \operatorname{Cos} \theta \cdot T_{0}}{\Delta H_{m} \rho_{s} R_{p}} \approx \frac{k}{\Delta H_{m} R_{p}} \quad \text { (Equation 1) }
$$

where $T_{p}$ is the melting temperature of a liquid confined in a pore of radius $R_{p}, T_{0}$ is the normal melting temperature of the liquid, $\sigma_{\mathrm{SL}}$ is the surface energy of the solid/liquid interface, $\theta$ the contact angle, $\Delta \mathrm{H}_{\mathrm{m}}$ is the melting enthalphy, $\rho_{\mathrm{S}}$ the density of the solid and $\mathrm{k}$ a constant.

The measurement of $\Delta \mathrm{T}$ by calorimetry or NMR technique leads to thermoporosimetry [16] and NMR cryoporometry [17] respectively. The advantages of both techniques have been discussed extensively [18]. 
As first proposed by Kuhn [19] in the 1950's, thermoporosimetry can also be of great value for soft networks characterization like polymeric gels [20]. In this case, the confinement is created by the meshes defining the 3-dimensional polymer network. The study of polymer architecture modification by thermoporosimetry requires knowledge of the behaviour of liquids able to swell these organic materials. We recently developed reference porous materials for calibration of thermoporosimetry with various solvents [21,22]. In our systematic work, we observed that some solvents presenting a low temperature phase transition in the solid state offered even more interest [23]. Indeed, this transition is also affected by the confinement and is an interesting alternative to the use of liquid to solid transition since it is usually much more energetic. From a practical point of view the use of these transitions does not change the procedure requiring the calibration of the technique with samples of known porosity. But from a fundamental point of view, this observation raises some questions about the underlying thermodynamics. The objective of this paper is to discuss the transitions of carbon tetrachloride in confined geometry because $\mathrm{CCl}_{4}$ is an effective solvent for polymer swelling and also presents this solid state phase transition as observed before. $[24,25]$.

\section{Theoretical considerations}

According to Equation (1), the shift of the transition temperature of a confined liquid $\Delta \mathrm{T}$ is inversely proportional to the radius of the pore in which it is confined. In fact it is well known that not all the solvent takes part in the transition and that a significant part of it remains adsorbed on the surface of the pore. The state of this adsorbed layer has been discussed extensively in the case of water. Consequently, the radius measured by application of the Gibbs-Thomson equation should be written $\mathrm{R}=\mathrm{R}_{\mathrm{p}}-\mathrm{t}$ where $\mathrm{t}$ is the thickness of the adsorbed layer leading to a reformulation [7] of Equation 1 as 


$$
R_{p}=\frac{k}{\Delta H_{m} \Delta T}+t \quad(\text { Equation } 2)
$$

The value of $t$ can be determined by the calibration procedure using materials of various pore sizes and this is the traditionally adopted procedure. The problem in doing so is that the underlying hypothesis is that the thickness of the adsorbed layer $t$ does not vary with pore size. For small pores, the error on $t$ can lead to large errors on the measurement of $R_{p}$.

We proposed an alternative method to measure $t$ by adding sequentially various amounts of liquid in the porous material [26]. As stated before this layer $t$ represents the part of the solvent which does not crystallize. For solvents like $\mathrm{CCl}_{4}$ which exhibit a further transition at low temperature the behaviour of this adsorbed layer is an open question. Does this solvent participate in the second transition? Is a new adsorbed layer created on the top of the first one? To get further insight into these questions we studied the behaviour of $\mathrm{CCl}_{4}$ in mesoporous silica gels in this paper as described in the following section.

\section{Experimental section}

\subsection{Mesoporous silica gels}

Mesoporous monolithic silica gels $(2.5 \mathrm{~mm} \times 5.6 \mathrm{~mm}$ diameter cylinders $)$ were prepared by the acid catalysed hydrolysis and condensation of a silicon alkoxide, following procedures reviewed elsewhere [27]. Careful control of the aging time performed at $900^{\circ} \mathrm{C}$ allowed the production of samples with controlled textural properties. In this study two samples (A and B) with different textural properties (Specific Surface Area (SSA), total pore volume $\left(\mathrm{V}_{\mathrm{p}}\right)$ and pore size distribution (PSD)) were used. The textural characteristics of the samples were determined by $\mathrm{N}_{2}$ sorption.

\subsection{Gas sorption measurements}

Textural data of the silica gels were determined on a Quantachrome Autosorb 1 apparatus. The instrument permits a volumetric determination of the isotherms by a discontinuous static 
method at $77.4 \mathrm{~K}$. The adsorptive gas was nitrogen with a purity of $99.999 \%$. The cross sectional area of the adsorbate was taken to be $0.162 \mathrm{~nm}^{2}$ for SSA calculations purposes. Prior to $\mathrm{N}_{2}$ sorption, all samples were degassed at $100^{\circ} \mathrm{C}$ for $12 \mathrm{~h}$ under reduced pressure. The masses of the degassed samples were used in order to estimate the SSA. The BET [28] SSA was determined by taking at least 4 points in the $0.05<\mathrm{P} / \mathrm{P}_{0}<0.3$ relative pressure range. The pore volume was obtained from the amount of nitrogen adsorbed on the samples up to a partial pressure taken in the range $0.994<\mathrm{P} / \mathrm{P}_{0}<0.999$. Pore size distributions were calculated from the desorption isotherm by the $\mathrm{BJH}$ method [29]. The mean pore radius $\mathrm{R}_{\mathrm{av}}$ was calculated according to

$$
R_{a v}=\frac{2 V_{p}}{S_{B E T}} \quad \text { (Equation 3) }
$$

corresponding to a cylindrical shape for the pores which is also the underlying hypothesis in equation (1).

Textural data for the two samples are displayed in Table 1. In this table, the modal pore diameter $R_{p}$ is also shown. This value fairly matches the $R_{a v}$ derived from $S_{B E T}$ measurement with cylindrical shape assumption thus confirming the validity of the hypothesis on the pore shape.

\begin{tabular}{ccccc}
\hline Sample & $\begin{array}{c}\mathrm{SSA} \\
\left(\mathrm{m}^{2} / \mathrm{g}\right)\end{array}$ & $\begin{array}{c}\mathrm{Vp} \\
\left(\mathrm{cm}^{3} / \mathrm{g}\right)\end{array}$ & $\begin{array}{c}\mathrm{R}_{\mathrm{av}} \\
(\mathrm{nm})\end{array}$ & $\begin{array}{c}\mathrm{R}_{\mathrm{p}} \\
(\mathrm{nm})\end{array}$ \\
\hline $\mathrm{A}$ & 183 & 1,327 & 14,5 & 14,25 \\
$\mathrm{~B}$ & 166 & 0,991 & 11,9 & 8,7 \\
\hline
\end{tabular}

Table 1: Porous characteristics of the silica gels samples. 


\subsection{DSC measurements}

A Mettler-Toledo DSC821 instrument calibrated (both for temperature and enthalpy) with metallic standards ( $\mathrm{In}, \mathrm{Pb}, \mathrm{Zn})$ and with n-heptane was used to record the thermal curves. It was equipped with an intracooler set allowing a scanning range of temperature between -70 and $600{ }^{\circ} \mathrm{C}$. About 10 or $20 \mathrm{mg}$ of the studied material was introduced into an aluminium DSC pan to undergo an appropriate temperature program. To allow the system to be in an equilibrium state, a slow freezing rate is required [30]. A rate of $-0.7^{\circ} \mathrm{C} / \mathrm{min}$ was chosen. Other slower cooling rates were tested which did not show any significant discrepancy. $\mathrm{CCl}_{4}$ (Aldrich) of HPLC quality was used without any supplementary purification.

\section{Results and discussion}

\subsection{Thermal behavior of free $\mathrm{CCl}_{4}$}

Bulk $\mathrm{CCl}_{4}$ was studied before and its thermal phase transitions were well characterized $[24,25]$. It exhibits a complex thermal transitions system as shown in Figure 1. 


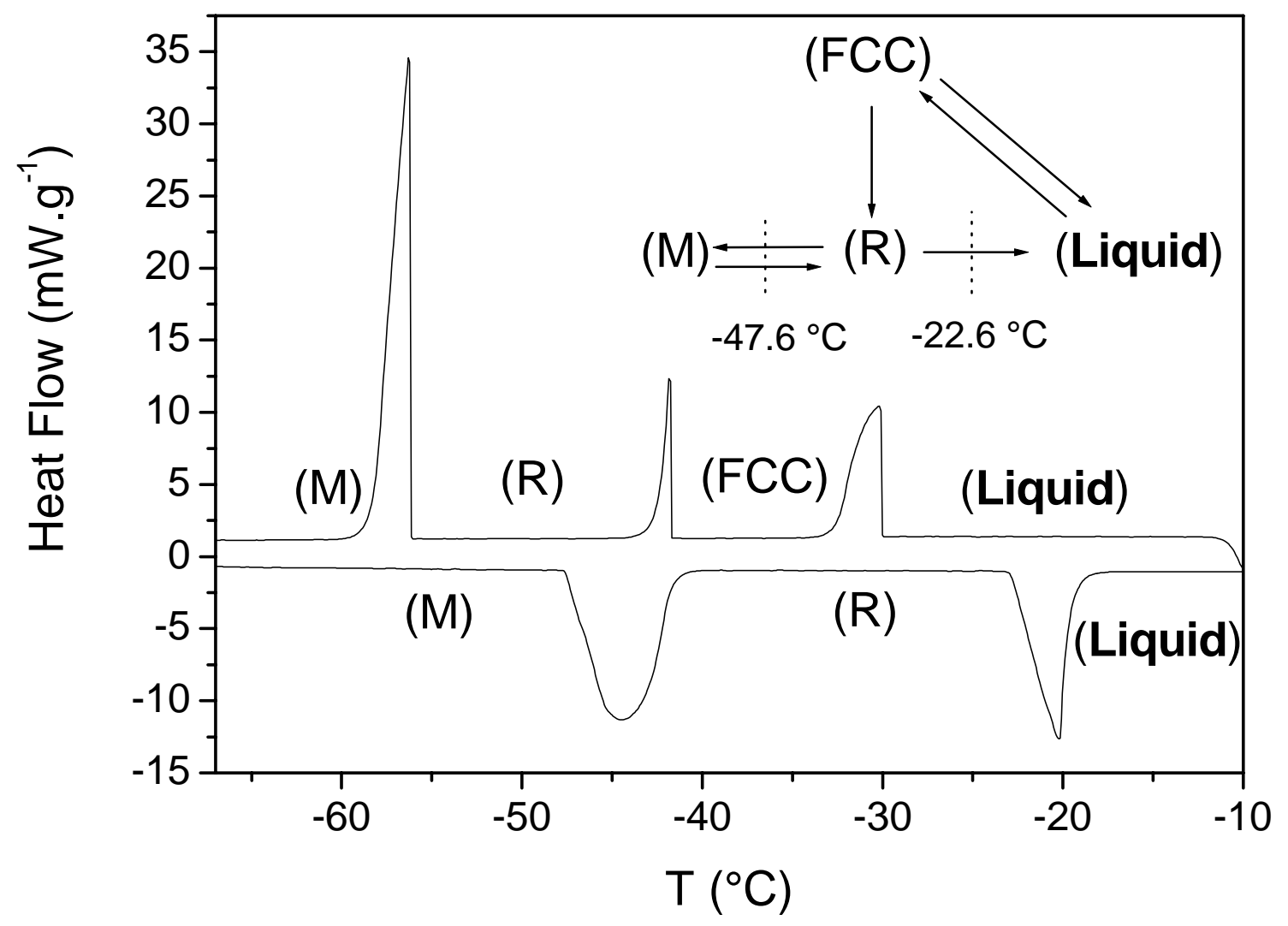

Figure 1: DSC thermogram of pure $\mathrm{CCl}_{4}$ showing the different transitions.

As it is cooled down, liquid $\mathrm{CCl}_{4}$ crystallizes into Face-Centered-Cubic phase (FCC) which follows a phase transition upon further cooling to a Rhombohedral one (R) which, in turn, transforms to Monoclinic crystalline structure $(\mathrm{M})$ around $-48^{\circ} \mathrm{C}$. Heating the $(\mathrm{M})$ phase leads to $(\mathrm{R})$ in a reversible way but upon heating $(\mathrm{R})$ melts directly without transforming into the (FCC) phase. Observing the transition heat values (Figure 1), it can be pointed out that the R to-liquid transition releases an enthalpy $(13.6 \mathrm{~J} / \mathrm{g})$ equivalent to the total heat liberated by the liquid-to-FCC $(9.6 \mathrm{~J} / \mathrm{g})$ together with the FCC-to-R $(3.8 \mathrm{~J} / \mathrm{g})$. Takei et al. [24] showed that both solid-to-solid and liquid-to-solid transitions of $\mathrm{CCl}_{4}$ were strongly dependent on the average pore size of the material in which the liquid is confined. In particular, they 
demonstrated that the FCC-to-R transition is no longer observed when the pore radius is smaller than $16.5 \mathrm{~nm}$, which is the case for our silica samples (see Table 1).

Because of the complex behaviour of $\mathrm{CCl}_{4}$ upon cooling, we chose to use the heating of the solvent to limit the study to the M-to-R and R-to liquid transitions.

The two transitions were studied for $\mathrm{CCl}_{4}$ confined in the two porous samples $\mathrm{A}$ and $\mathrm{B}$.

\subsection{Thermal behaviour of $\mathrm{CCl}_{4}$ confined in sample A}

The objective is to get quantitative information on the solvent undergoing both transitions (both confined and free solvent). In order to do so, we performed sequential addition of precise quantities of $\mathrm{CCl}_{4}$ in the sample as described in [26]. Briefly, a known mass of silica gel (about $20 \mathrm{mg}$ ) is set in the DSC pan which is sealed. A small hole is drilled in the cover allowing further injection of known masses of carbon tetrachloride. This procedure allows a precise control of the added mass of solvent. After each thermal cycle, a new injection is performed.

For the first time to our knowledge, we also performed some experiments in the reverse way, by progressively evaporating the solvent starting from a large excess. This was performed by inert gas flushing in the DSC pan at $25{ }^{\circ} \mathrm{C}$. The subsequent evaporation of the solvent is controlled by the flushing time. Obviously in this case we do not know the remaining mass of $\mathrm{CCl}_{4}$, but we can calculate it from the measured enthalpies.

The thermograms recorded for various quantities of $\mathrm{CCl}_{4}$ added to sample $\mathrm{A}$ are shown in Figure 2. In this figure, 4 peaks can be observed which are labelled from 1 to 4 starting from low temperature to room temperature. The assignment of all peaks is presented in Table 2.

\begin{tabular}{cccc}
\hline Peak 1 & Peak 2 & Peak 3 & Peak 4 \\
\hline $\mathrm{M} \rightarrow \mathrm{R}$ & $\mathrm{M} \rightarrow \mathrm{R}$ & Melting of R & Melting of R \\
confined solvent & free solvent & Confined solvent & free solvent \\
\hline
\end{tabular}


Table 2: Labelling of the different peaks observed in the DSC curves.

Figure 3 presents the DSC curves recorded upon desorbing the $\mathrm{CCl}_{4}$ by gas flushing. As can be seen in the figure, the control of the flushing time allows a slow evaporate of the liquid and a discrimination of all the steps. What is interesting in this experiment is that the whole set of experiments can be programmed automatically thus giving a considerable amount of experimental data.

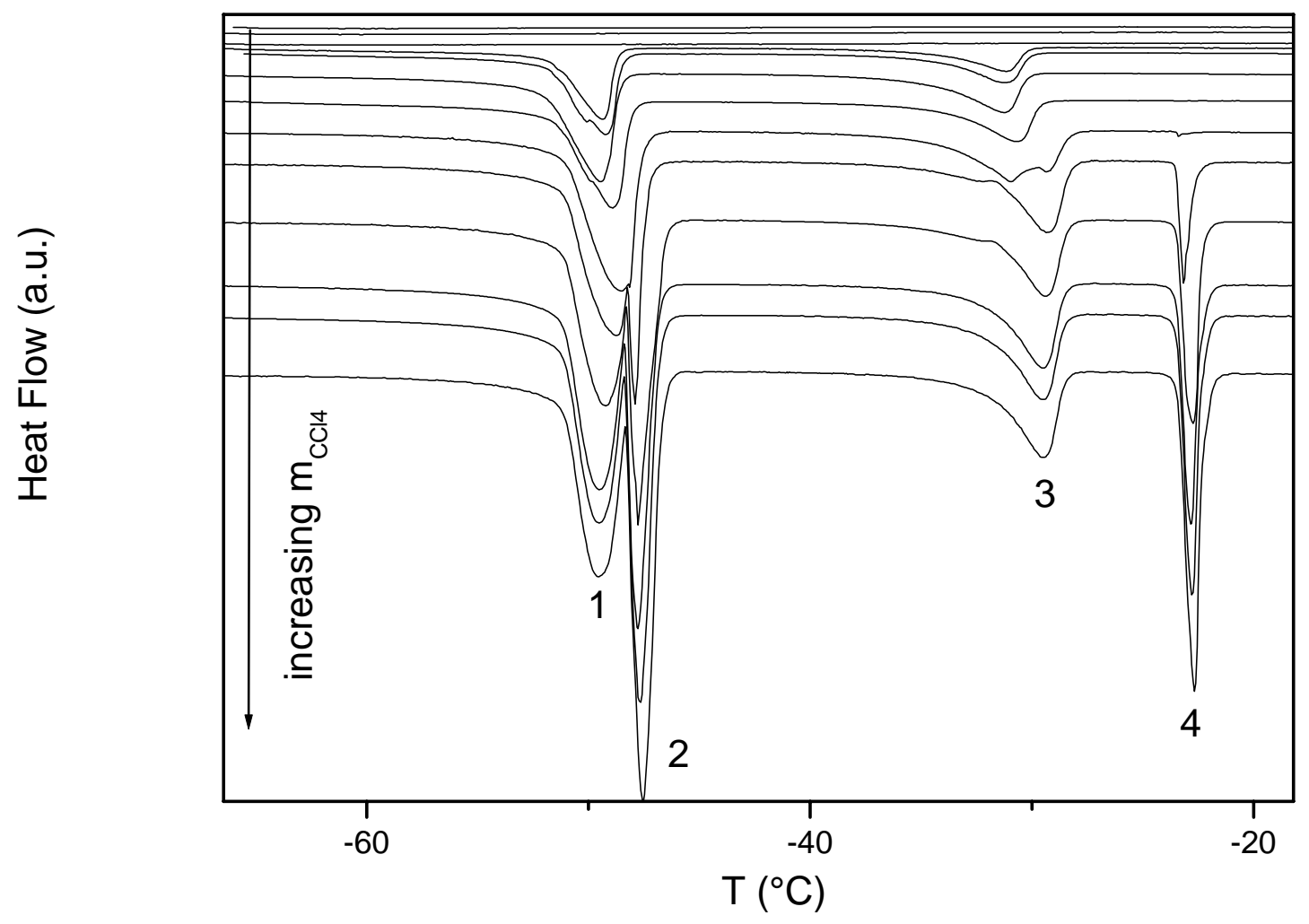

Figure 2: Thermograms recorded for various amount of $\mathrm{CCl}_{4}$ added to sample A. 


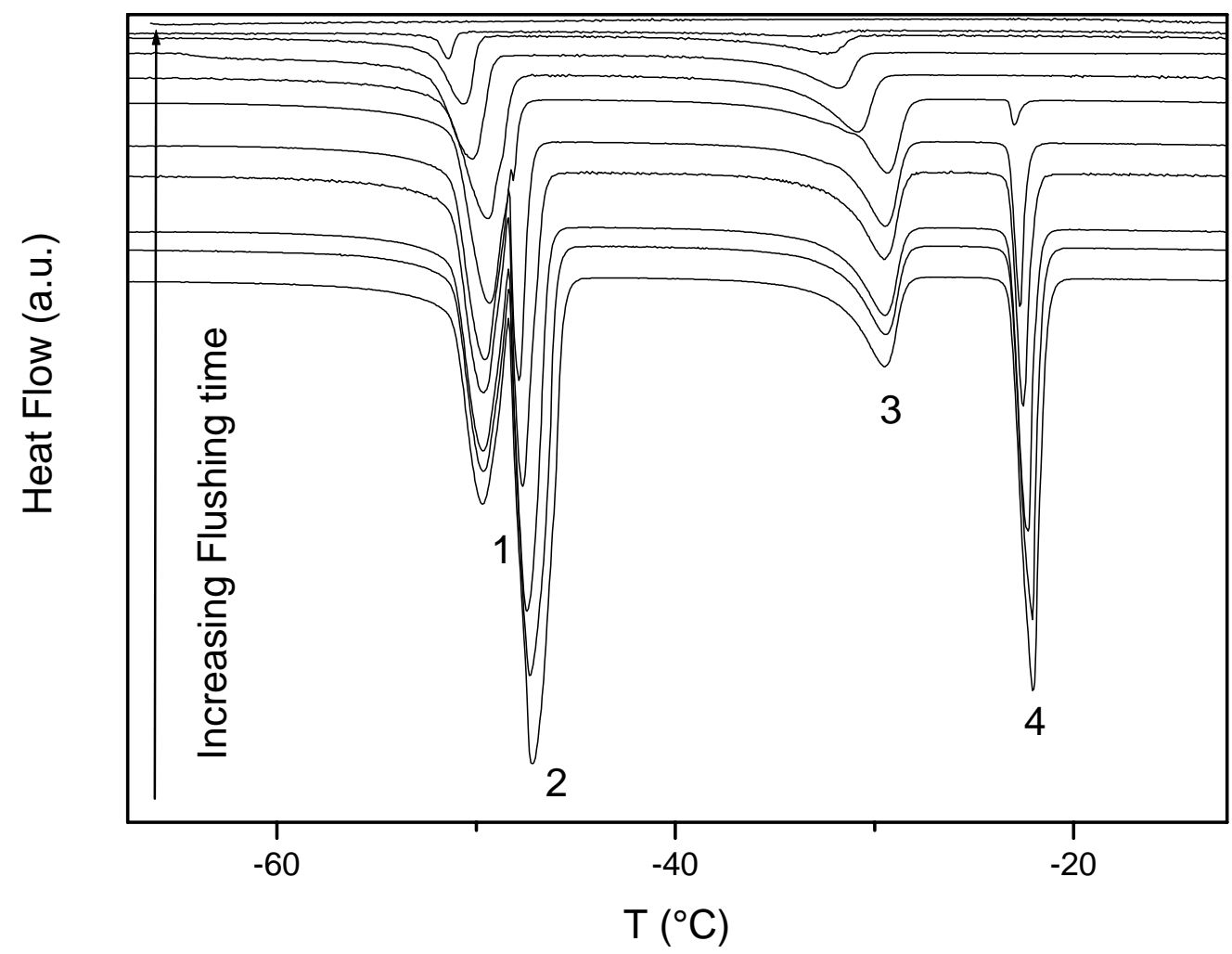

Figure 3: Thermograms recorded for various flushing times for sample A filled with $\mathrm{CCl}_{4}$.

In Figure 2, it can be seen that for small quantities of added $\mathrm{CCl}_{4}$, no transition is observed. This first step corresponds to the creation of the adsorbed layer $t$ onto the surface of the porous silica gel. For higher amounts of $\mathrm{CCl}_{4}$, peak 3 appears at a temperature shifted with respect to the normal melting temperature of solid $\mathrm{CCl}_{4}$. At about the same time, peak 1 also appears corresponding to the M-to- $\mathrm{R}$ transition for the confined solvent. The intensities of these two peaks increase upon further addition of solvent until they remain constant coinciding with the appearance of peaks 2 and 4 corresponding to excess free solvent. A plot of the heats corresponding to peaks 3 and $4(\mathrm{H} 3$ and $\mathrm{H} 4)$ as a function of the mass of $\mathrm{CCl}_{4}$ added $\left(\mathrm{m}_{\mathrm{CC} 14}\right)$ is presented in Figure 4 . The different steps are clearly observable. The point where $\mathrm{H} 3$ is different from zero corresponds to the end of the creation of the adsorbed layer 
allowing the determination of the quantity of solvent $\left(\mathrm{m}_{\mathrm{t}}\right)$ participating in the formation of this layer. At a given point, $\mathrm{H} 3$ remains constant and this point corresponds to the total filling of the pores $\left(\mathrm{H} 3_{\mathrm{Max}}\right)$ thus allowing the determination of the porous volume of the sample (see section 3.4).

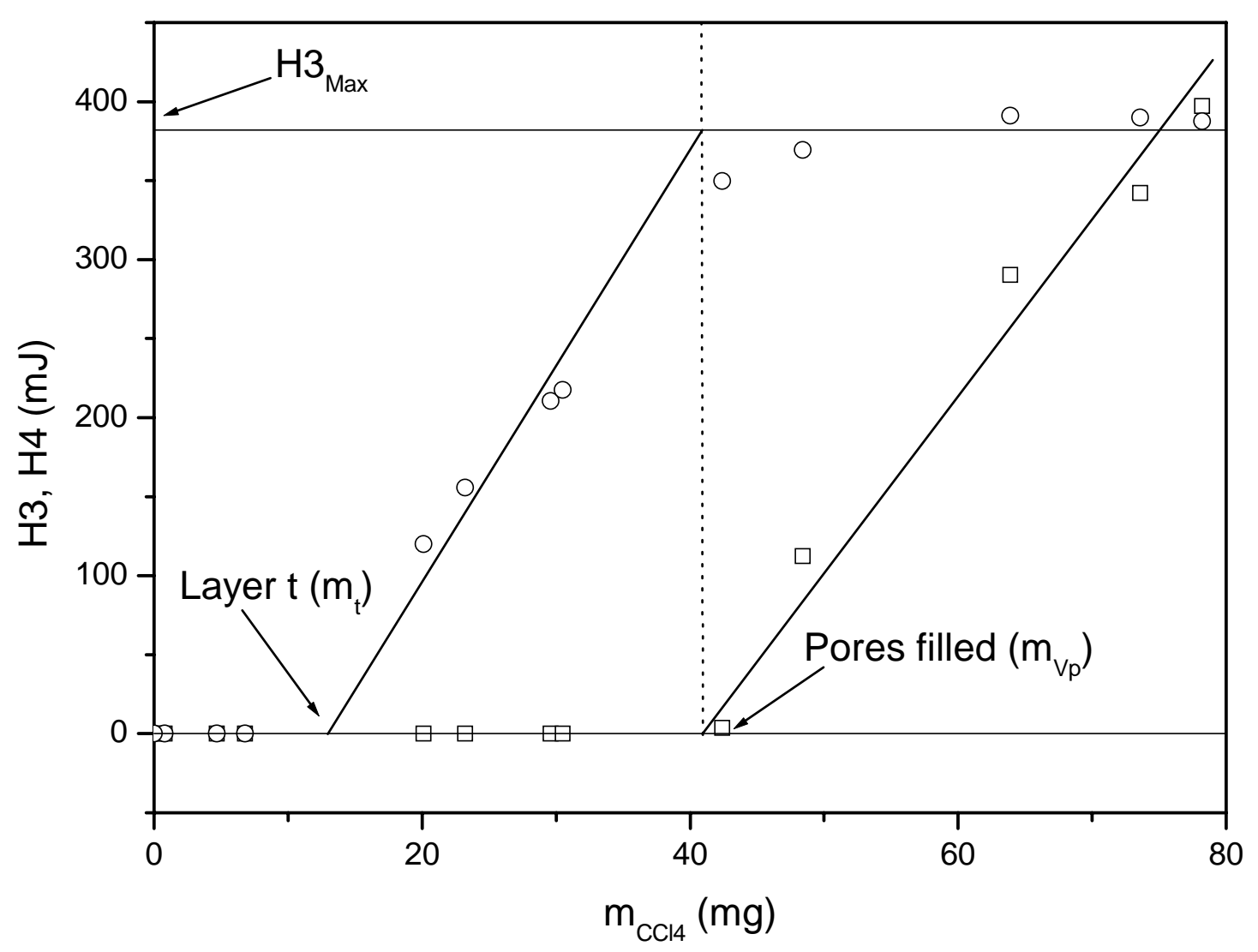

Figure 4: Evolution of $\mathrm{H} 3$ (circles) and $\mathrm{H} 4$ (squares) as a function of the mass of $\mathrm{CCl}_{4}$ added in sample A.

To measure the amounts of $\mathrm{CCl}_{4}$ involved in each transition precisely, we need to know the transition enthalpy at the given temperature. These values are known for free solvent transiting at regular temperatures but not for confined solvent which undergoes transitions at lower temperature. From Figure 4, we can measure $\mathrm{H} 3_{\mathrm{Max}}$ at the point where all pores are 
filled in the constant part of the curve. In this case the enthalpy corresponds to a mass of solvent equal to the total mass added $\left(\mathrm{m}_{\mathrm{vp}}\right)$ minus the mass required for the creation of the adsorbed layer $\left(\mathrm{m}_{\mathrm{t}}\right)$ namely $\mathrm{m}=\mathrm{m}_{\mathrm{vp}}-\mathrm{m}_{\mathrm{t}}$. We can then deduce the enthalpy of melting per gram for the confined solvent $\Delta \mathrm{H} 3=13.67 \mathrm{~J}^{-g^{-1}}$.

For the M-to-R transition, the situation is different. Because of the overlapping of peaks 1 and 2 we can only use the sum $\mathrm{H} 1+\mathrm{H} 2$. If we plot the evolution of $\mathrm{H} 3$ and $\mathrm{H} 4$ as a function of $(\mathrm{H} 1+\mathrm{H} 2)$ we obtained the curves presented in Figure 5.

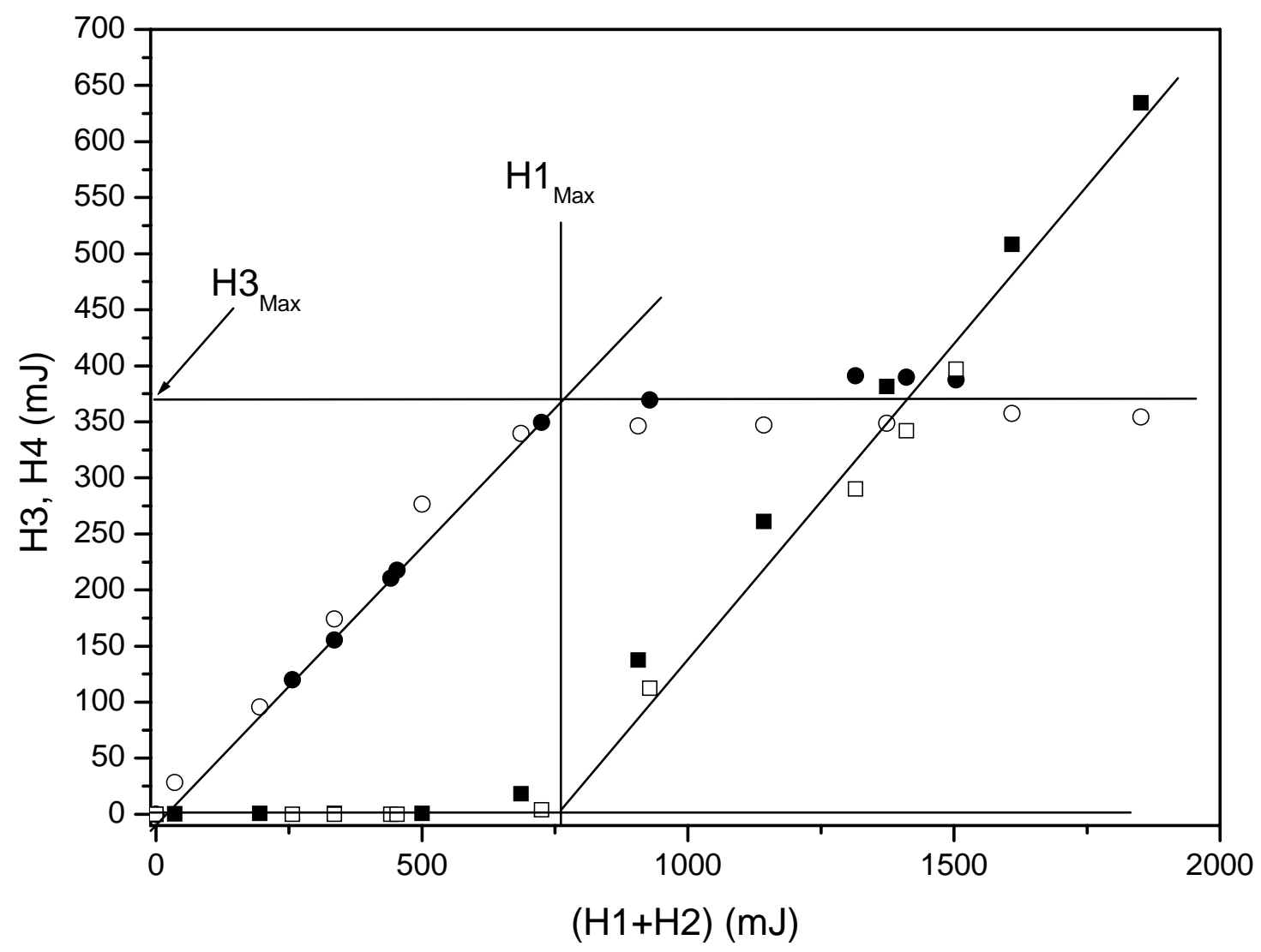

Figure 5: Evolution of H3 (circles) and H4 (squares) for progressive filling (full symbols) and desorption (empty symbols) as a function of $(\mathrm{H} 1+\mathrm{H} 2)$. 
It is worth noting that the points corresponding to desorption experiments complete nicely the points corresponding to sequential addition of solvent (empty and full symbols respectively). The point where $\mathrm{H} 4$ differs from zero corresponds to the $\mathrm{H} 1_{\mathrm{Max}}$ value corresponding to the totality of solvent undergoing the transition (in this case $\mathrm{H} 2=0$ ). The enthalpy of transition

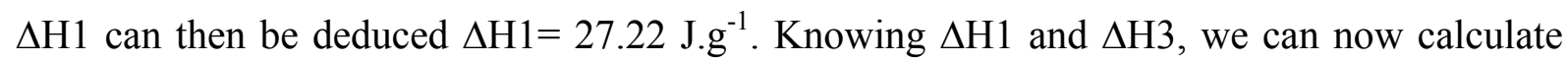
the masses of solvent which undergo the various transitions for all points. Figure 6 presents the correlation between these masses M3 and M1 (the indexes correspond to the different peaks).

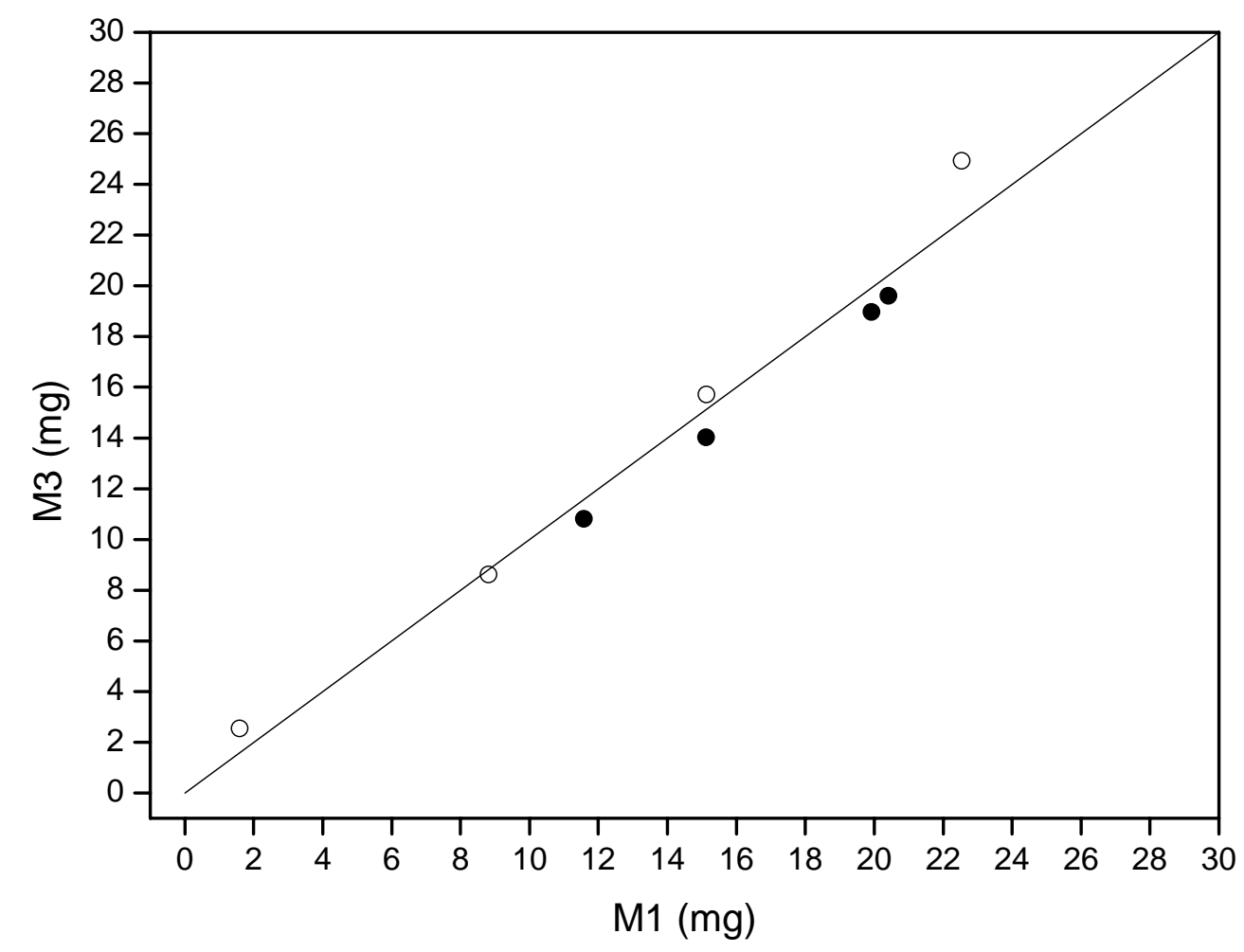

Figure 6: Evolution of the mass of confined solvent undergoing transition M-to-R (M1) as a function of the mass of confined solvent undergoing the R-to-liquid transition (M3). Progressive filling $(\bullet)$ and desorption $(\circ)$ experiments. The line $\mathrm{y}=\mathrm{x}$ is also plotted. 
A clear correlation is observed between the confined solvent which undergoes the R-tliquid and the M-to-R transitions. This correlation is observed both for addition and evaporation experiments. This clearly confirms that all solvent undergoing the first transition also undergoes the second one.

This observation is further confirmed by the plot of Figure 7 showing the correlation between M2 and M4, the masses of free solvent which undergo the transitions 2 and 4. M2 is determined through the following equation:

$$
M 2=\frac{(H 1+H 2)-H 1_{\text {Max }}}{\Delta H 2} \quad \text { Equation (4) }
$$

where $\mathrm{H} 1_{\text {Max }}$ is the enthalpy required for the M-to- $\mathrm{R}$ transition of the liquid totally filling the pores (see Figure 5) and $\Delta \mathrm{H} 2=46.6 \mathrm{~J}_{\mathrm{g}}{ }^{-1}$ the specific enthalpy for the M-to-R transition of free $\mathrm{CCl}_{4}$.

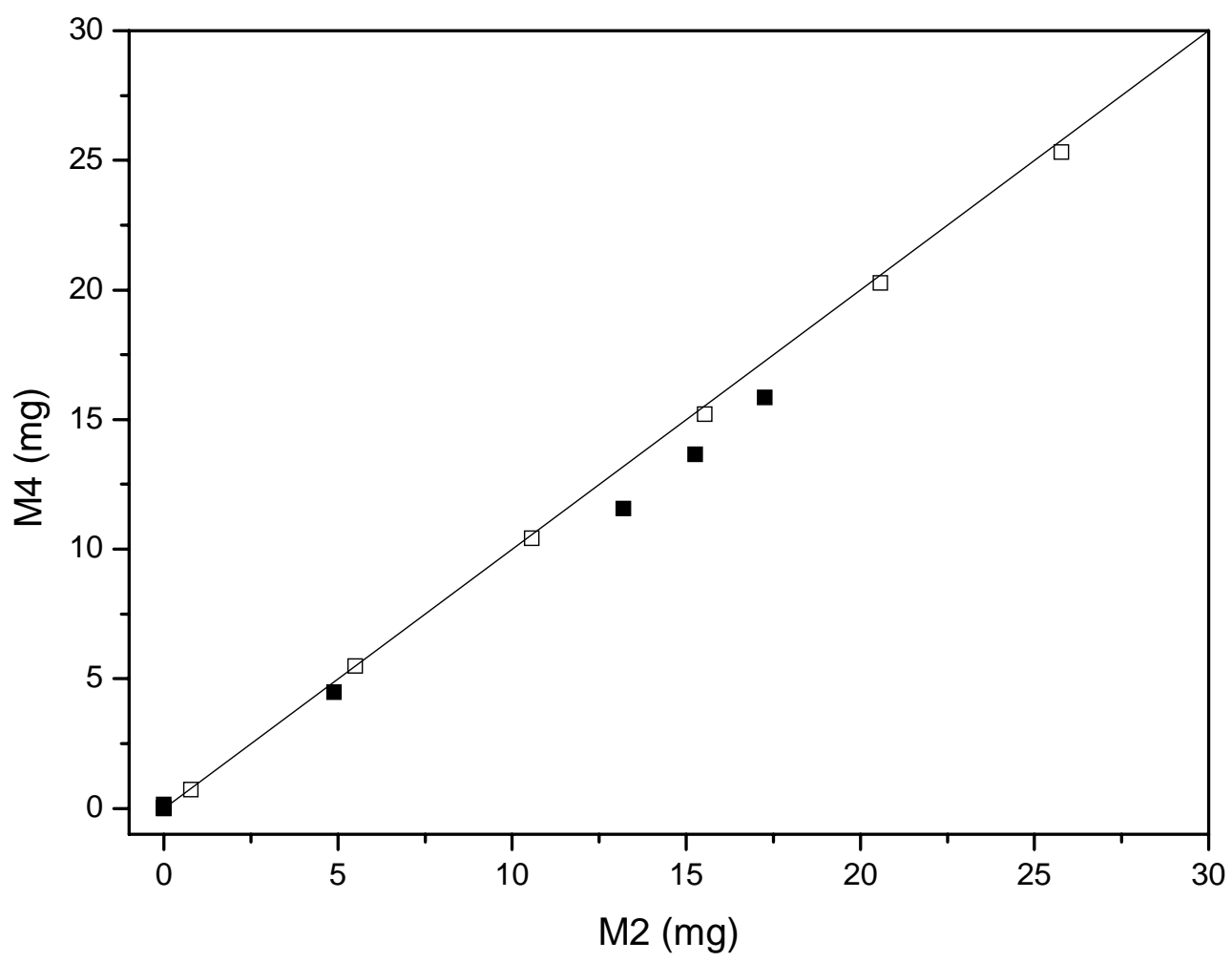


Figure 7: Correlation between the masses of free solvent undergoing the R-to-liquid (M2) and the M-to-R transitions (M4). Progressive filling ( $\square$ ) and desorption ( $\square$ ) experiments. The $\mathrm{y}=\mathrm{x}$ line is also plotted.

Once again a clear correlation is observed between the two quantities confirming that all the solvent which has crystallised outside the pores undergoes the second transition at a regular temperature (no confinement). These conclusions also demonstrate that the layer t remains adsorbed and does not participate in the low temperature transition.

\subsection{Thermal behaviour of $\mathrm{CCl}_{4}$ confined in sample $\mathrm{B}$}

The same experiments and calculations were applied to sample B which presents smaller pores i.e. higher confinement.

The thermograms recorded for sample $\mathrm{B}$ filled with $\mathrm{CCl}_{4}$ upon progressive evaporation are displayed in Figure 8. Because of the higher degree of confinement, the two peaks 1 and 2 are well resolved and can be discriminated. 


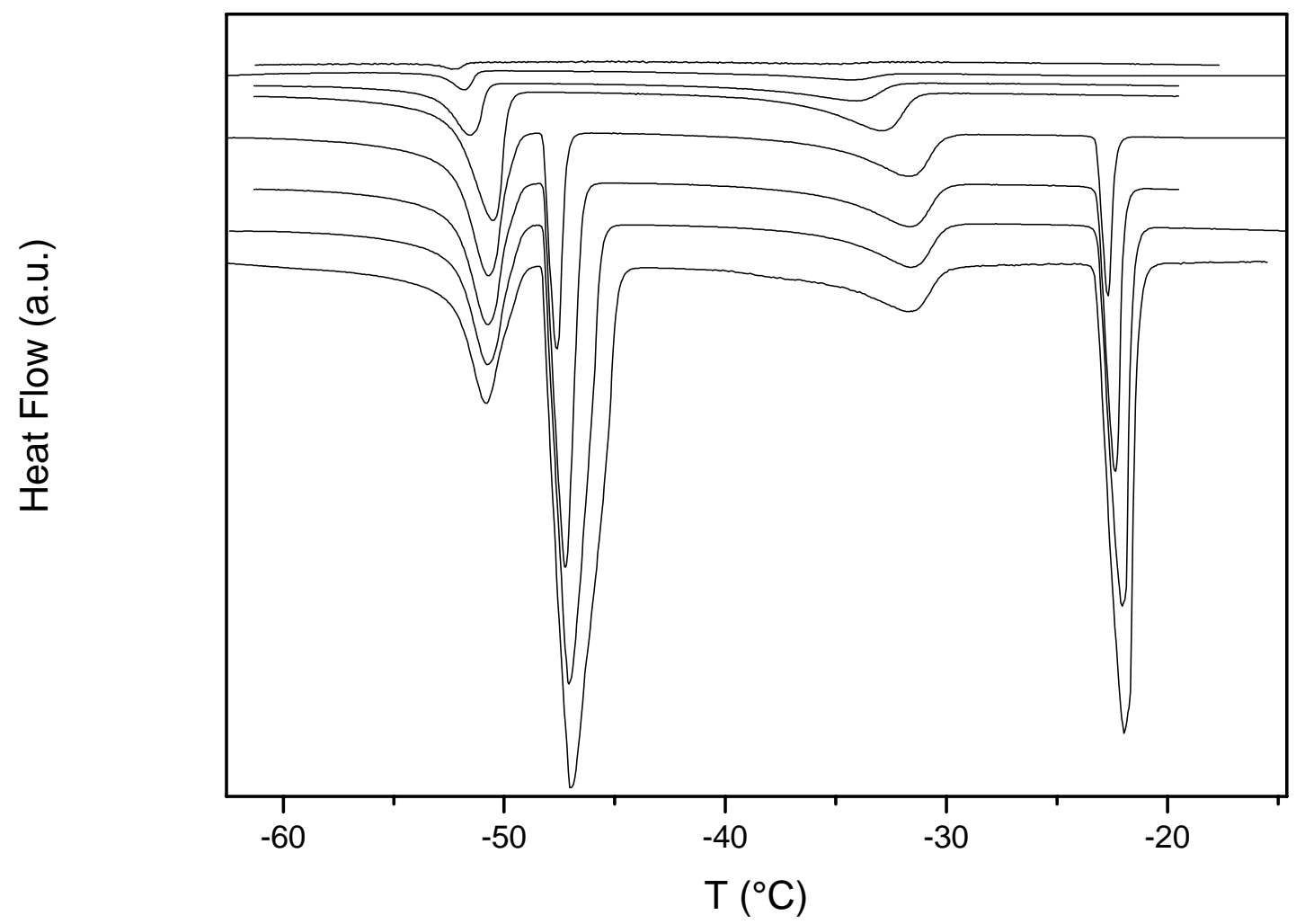

Figure 8: Thermograms recorded for various flushing times for sample B filled with $\mathrm{CCl}_{4}$.

Following the same procedure, we can plot the evolution of $\mathrm{H} 3$ and $\mathrm{H} 4$ as a function of $\mathrm{m}_{\mathrm{CCl} 4}$ as performed in Figure 9. 


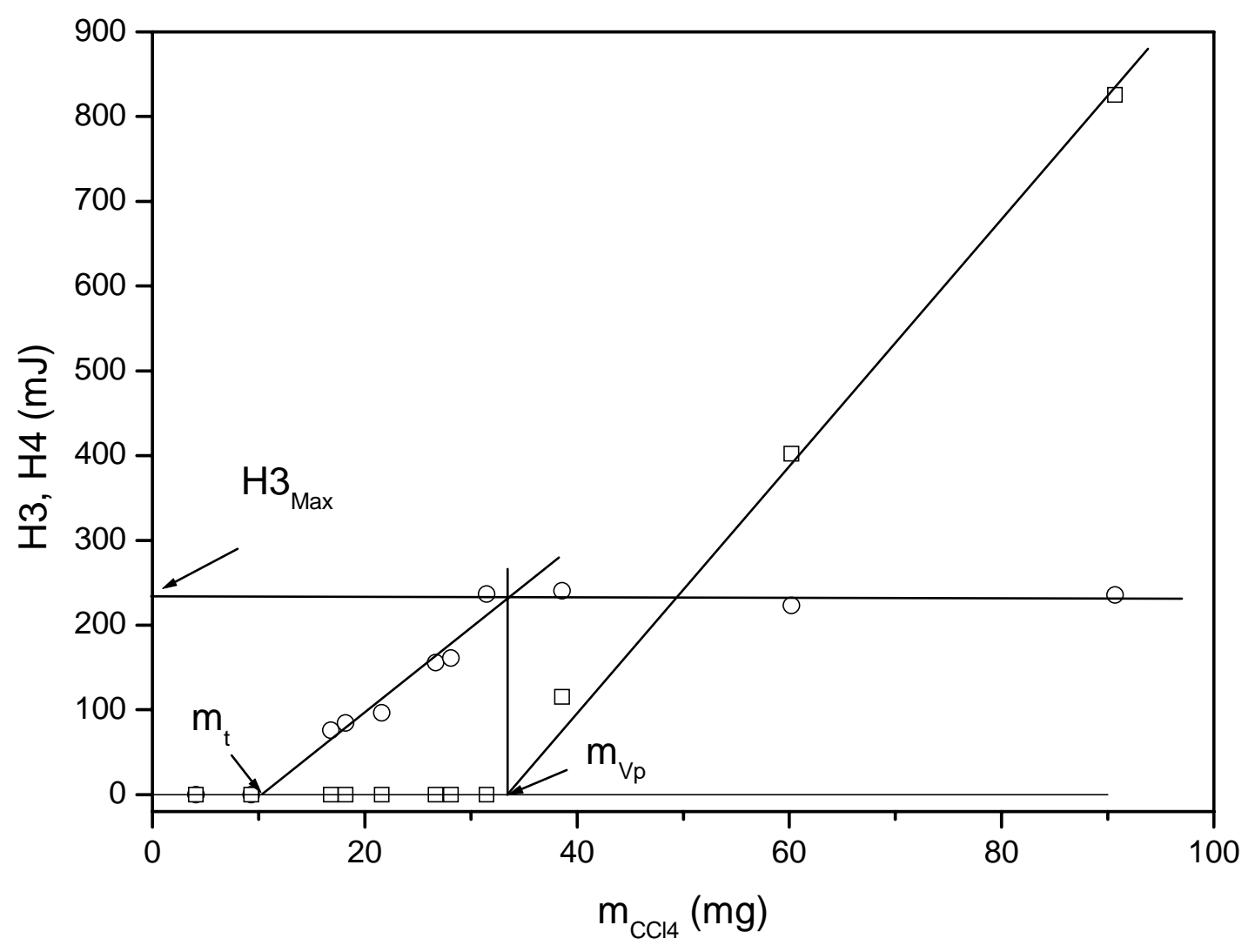

Figure 9: Evolution of $\mathrm{H} 3$ (circles) and $\mathrm{H} 4$ (squares) as a function of the mass of $\mathrm{CCl}_{4}$ added in sample $B$.

The plot of $\mathrm{H} 1$ and $\mathrm{H} 2$ as a function of $\mathrm{m}_{\mathrm{CCl} 4}$ (not shown here) can also be performed.

From these curves, $\Delta \mathrm{H} 1$ and $\Delta \mathrm{H} 3$ for sample $\mathrm{B}$ can be derived $\left(\Delta \mathrm{H} 1=22.19 \mathrm{J.g}^{-1}\right.$ and $\left.\Delta \mathrm{H} 3=10.13 \mathrm{J.g}^{-1}\right)$. Together with the known values of $\Delta \mathrm{H} 2\left(46.6 \mathrm{J.g}^{-1}\right)$ and $\Delta \mathrm{H} 4\left(25.07 \mathrm{J.g}^{-1}\right)$ they allow the calculation of the quantities of solvent which undergo the different transitions for the various experiments. 


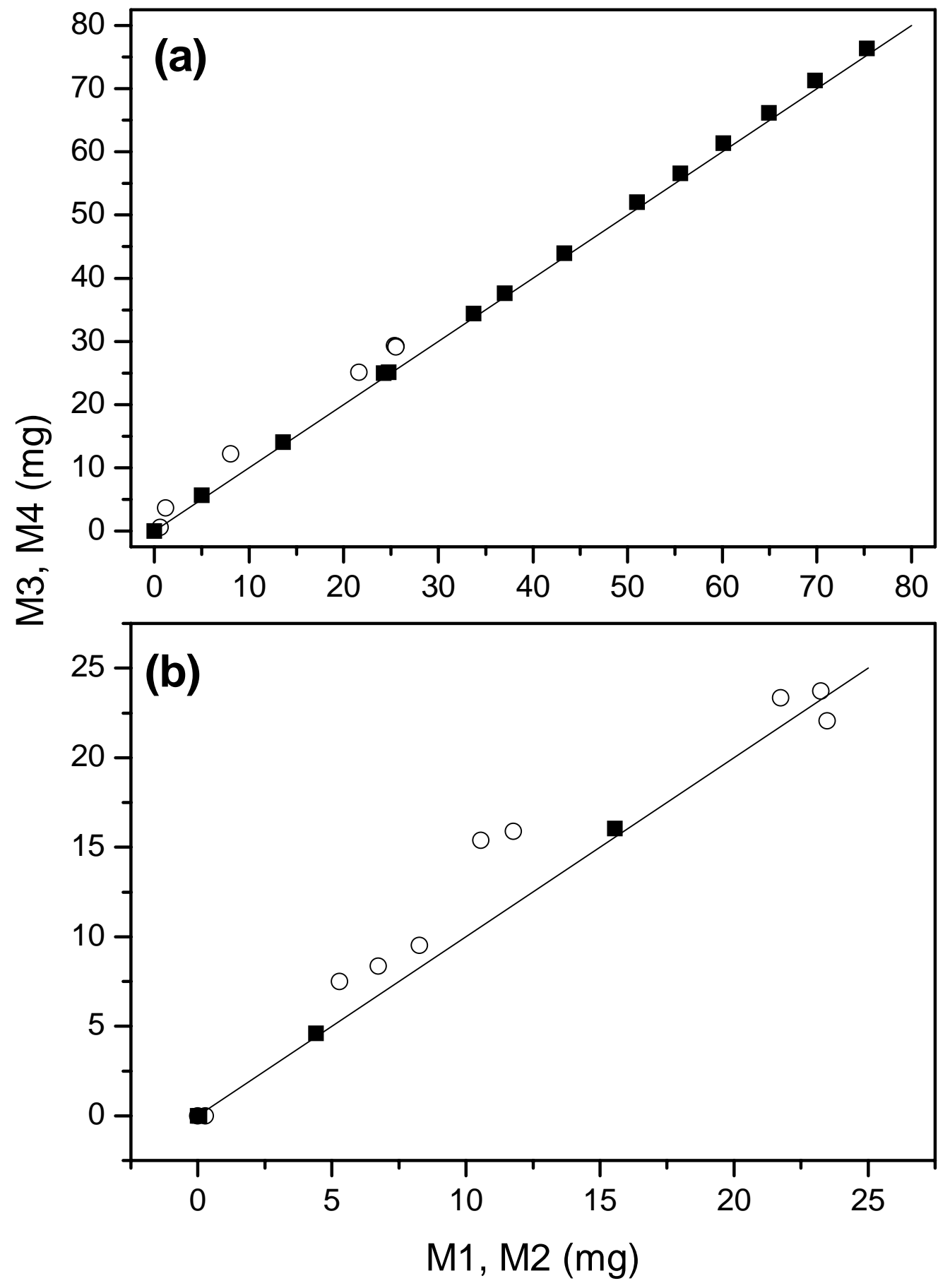

Figure 10: Correlation between M3 and M1 (circles) and M2 and M4 (squares) for progressive filling of the pores (b) and evaporation (a). 
The quantities M1, M2 M3 and M4 are plotted in Figure 10 both for progressive filling and evaporation experiments. A clear correlation between M3 and M1 on the one hand and between M4 and M2 on the other hand is observed confirming the conclusions drawn from the study of sample A. Scheme 1 depicts the global behaviour of $\mathrm{CCl}_{4}$ inside the porous silica recapitulating the different steps and the main conclusions of this work.

\section{$m$ increases}

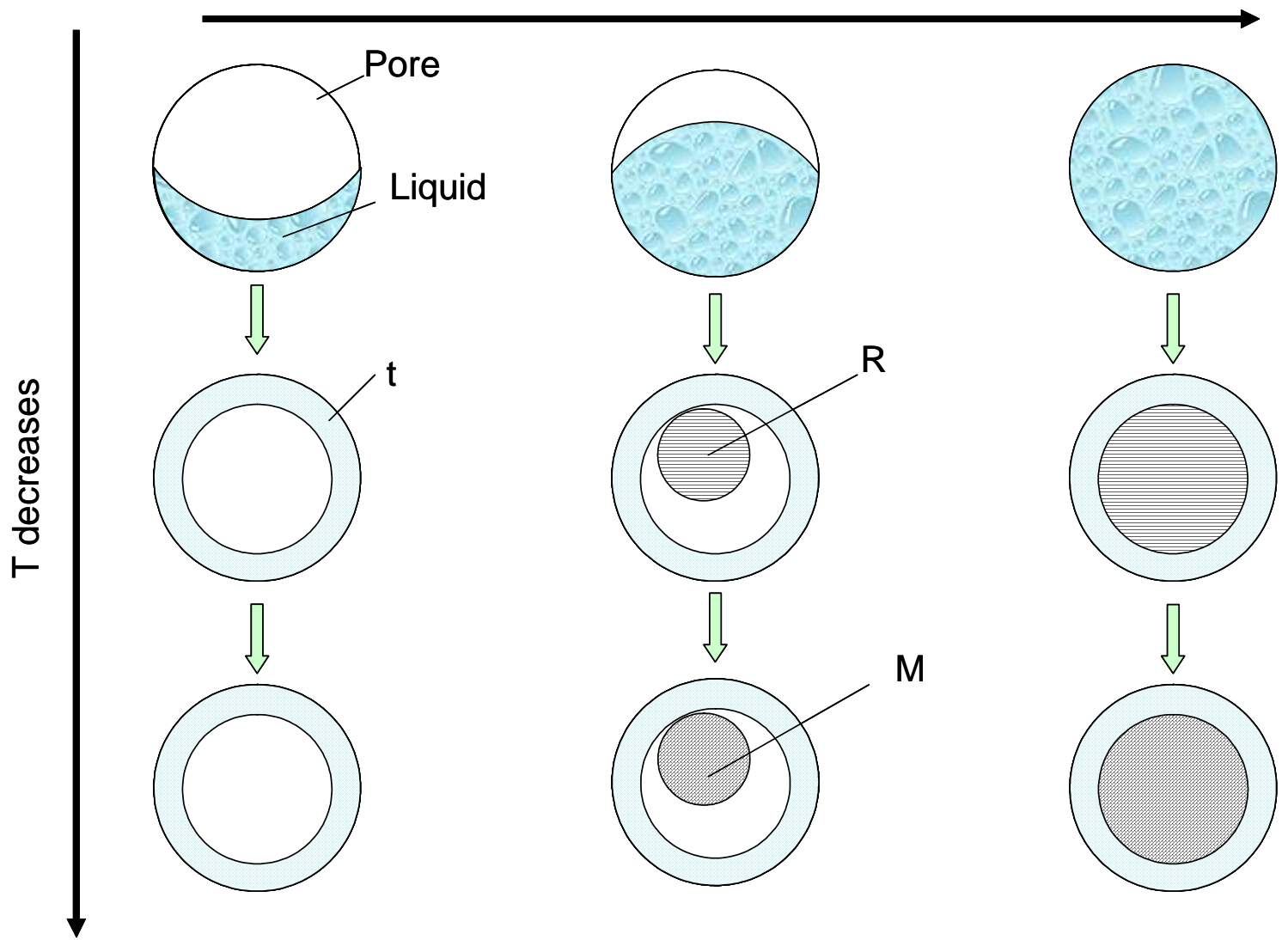

Scheme 1: Global behaviour of confined $\mathrm{CCl}_{4}$ in porous materials, $\mathrm{R}$ is the Rhombohedral phase, $\mathrm{M}$ the monoclinic one, $\mathrm{t}$ the adsorbed layer.

\subsection{Calculation of porous volumes and thicknesses of adsorbed layers}

Considering the curves of Figure 4 and 9 , we can measure the mass of solvent corresponding to total filling of the pore $\mathrm{m}_{\mathrm{vp}}$. The porous volume of the gel can then be calculated according to: 


$$
V_{p}=\frac{m_{v_{p}}}{\rho \cdot m_{\mathrm{siO}_{2}}} \quad \text { Equation (5) }
$$

$\rho$ being the density of $\mathrm{CCl}_{4}$. We took the value at $-20^{\circ} \mathrm{C}\left(\rho=10.85 \mathrm{kmol} . \mathrm{m}^{-3}\right)[31]$.

From the same figures, we can also measure the mass of the adsorbed layer $\mathrm{m}_{\mathrm{t}}$, the thickness of this layer can be calculated according to:

$$
t=\frac{m_{t}}{\rho \cdot S S A \cdot m_{\mathrm{SiO}_{2}}} \quad \text { Equation (6) }
$$

SSA being the specific surface area of the silica sample given in Table 1.

The results are summarized in Table 3.

\begin{tabular}{cccc}
\hline Sample & $\mathrm{V}_{\mathrm{p}}\left(\mathrm{cm}^{3} \cdot \mathrm{g}^{-1}\right)$ & $\mathrm{V}_{\mathrm{N} 2}\left(\mathrm{~cm}^{3} \cdot \mathrm{g}^{-1}\right)$ & $\mathrm{t}(\mathrm{nm})$ \\
\hline $\mathrm{A}$ & 1.35 & 1.327 & 2.3 \\
$\mathrm{~B}$ & 0.99 & 0.991 & 1.9 \\
\hline
\end{tabular}

The calculated value of $V_{p}$ are in very good agreement with the value measured by nitrogen sorption, the error is less than $2 \%$. The values of $t$ determined for samples $\mathrm{A}$ and $\mathrm{B}$ are also in good agreement with average value given in [25] after calibration procedure with samples of various pore size.

All calculations were performed with a constant value of $\rho_{\mathrm{CCl} 4}$ measured at $-20^{\circ} \mathrm{C}$. Obviously no information can be found in the literature for densities of carbon tetrachloride at lower temperatures since it is usually solid at these temperatures. Nevertheless using the value at $-20^{\circ} \mathrm{C}$, the error must be small. Furthermore, with the validity of such an approach demonstrated, we can now consider the exact porous volume to calculate the exact density of the confined solvent at various low temperatures. 


\section{Conclusions}

The thermal behavior of carbon tetrachloride confined in two mesoporous silica gels of different porosity was studied. The two transitions (solid to liquid and Monoclinic to Rhombohedral) were measured and are affected by the confinement. The enthalpies of these two transitions were determined for the first time at the temperatures corresponding to confined solvent. Using these enthalpies, a clear correlation has been shown between the solvent undergoing the first and the second transitions. Consequently, the adsorbed layer which is created during the intrusion of $\mathrm{CCl}_{4}$ inside the porosity of the silica gels is kept constant and does not participate in the two transitions. The thickness of this layer was measured for both samples and is found to be slightly dependant on the pore radius. Finally the porous volumes of the silica gels have been measured and the values agree very closely with those derived from nitrogen sorption isotherm. It has been demonstrated that using porous samples of known porosity (measured by mercury intrusion porosimetry or gas sorption analysis) could allow the measurement of thermodynamical data of confined liquids (Enthalpy of transition, density,....).

\section{Acknowledgements}

Financial support from the French ANR under project Nanothermomécanique (ACI Nanosciences $\mathrm{N}^{\circ} 108$ ) is gratefully acknowledged. The authors would like to thank A. Gordon and Pr S. Turrell for careful reading of the paper. 


\section{Contact author for correspondence and return of proofs:}

Dr Jean-Marie Nedelec

TransChiMiC, Laboratoire des Matériaux Inorganiques (CNRS UMR 6002)

Université Blaise Pascal, 24 Avenue des Landais, 63177 Aubière, FRANCE

Tel : 0033473407195

Fax 0033473407108

e-mail : j-marie.nedelec@univ-bpclermont.fr 


\section{References}

[1] H.K. Christenson, J. Phys.: Condens. Matter,13, 95, (2001)

[2] J. Dore, Chem. Phys., 258, 327, (2000).

[3] B. Webber and J. Dore, J. Phys. Condens. Matter, 16, 5449, (2004).

[4] C.T. Kresge, M.E. Leonowicz, W.J. Roth, J.C. Vartuli, J.S. Beck, Nature., 359, 710, (1992)

[5] M.P. Pileni, J. Phys. Chem. B, 105 (17), 3358, (2001).

[6] C.B.Murray, C.R. Kagan, M.G.Bawendi, Ann. Rev. Mat. Sci., 30, 545, (2000).

[7] B. Capoen, T. Gacoin, J.M. Nedelec, S. Turrell, M. Bouazaoui, J. Mat. Sci., 36(10), 2565, (2001).

[8] F. Gao, Q.Y. Lu, X.Y. Liu, Y.S. Yan and D.Y. Zhao, Nano Letters, 1 (12), 743, (2001)

[9] J. Kim, J.E. Lee, J. Lee, J.H. Yu, B.C. Kim, K. An, Y. Hwang, C.H. Shin, J.G. Park, J. Kim, T. Hyeon, J. Am. Chem. Soc., 128 (3), 688, (2006).

[10] S. Mann, Nature, 365(6446), 499, (1993).

[11] A.P. Alivisatos, Science, 289 (5480), 736, (2000).

[12] X.N. Yang, A. Alexeev, M.A.J. Michels, J. Loos, Macromolecules, 38 (10), 4289, (2005).

[13] J. Gibbs, Collected works, New Haven, CT : Yale University Press, (1928).

[14] S.W. Thomson, Phil. Mag., 42, 448, (1871).

[15] C.L. Jackson and G.B. Mc Kenna, J. Chem. Phys., 93(12), 9002, (1990).

[16] M. Brun, A. Lallemand, J-F. Quinson and C. Eyraud. Thermochim. Acta, 21, 59, (1977).

[17] J. Strange, M. Rahman and E. Smith, Phys. Rev. Lett., 71(21), 3589, (1993).

[18] J.M. Nedelec, J.P.E. Grolier and M. Baba, J. Sol-Gel Sci. Techn., 40, 191, (2006).

[19] W. Kunh, E. Peterli and H. Majer, J. Polymer Sci., 16, 539, (1955).

[20] M. Baba, J.M. Nedelec, J. Lacoste, J.L. Gardette, M. Morel, Polym. Degrad. Stabil., 80(2), 305, (2003).

[21] N. Billamboz, M. Baba, M. Grivet and J.M. Nedelec, J. Phys. Chem. B, 108, 12032, (2004).

[22] N. Bahloul, M. Baba and J.M. Nedelec, J. Phys. Chem. B, 109, 16227, (2005). 
[23] M. Baba, J.M. Nedelec, J. Lacoste and J.L. Gardette, J. Non-Cryst. Solids, 315, 228, (2003).

[24] T. Takei, Y. Ooda, M. Fuji, T. Watanabe, M. Chikazawa, Thermochim. Acta, 352-353, 199, (2000).

[25] B. Husár, S. Commereuc, L. Lukáč, S. Chmela, J.M. Nedelec and M. Baba, J. Phys. Chem. B, 110, 5315, (2006).

[26] M. Baba, J.M. Nedelec and J. Lacoste, J. Phys. Chem. B, 107, 12884, (2003).

[27] L.L. Hench, in Sol-gel silica : processing, properties and technology transfer, Noyes Publications, New York, (1998).

[28] S. Brunauer, P.H. Emmet and E. Teller, J. Am. Chem. Soc., 60, 309, (1938).

[29] E.P. Barret, L.G. Joiner and P.P. Halenda, J. Am. Chem. Soc., 73, 373, (1951).

[30] R. Landry, Thermochim. Acta, 433(1-2), 27, (2005).

[31] Dipper, NIST Standard References Database v.9.0 (1985). 